\title{
Knowledge, Attitude and Practice of Oral and Dental Healthcare in Pregnant Women
}

\section{Sunita Bamanikar and Liew Kok Kee}

Received: 06 Apr 2013 / Accepted: 28 May 2013

(c) OMSB, 2013

\section{Abstract}

Objectives: Pregnant women are more susceptible to periodontal disease like gingivitis. Periodontal disease may be associated with adverse pregnancy outcomes. There is no published literature on dental health in pregnant women in Brunei, Darussalam. The objective of this study was to assess women's knowledge and attitude towards oral and dental health during pregnancy and to examine their self-care practices in relation to oral and dental health. This study was carried out at the maternal child health clinic, Jubli Perak Sengkurong Health Centre, Brunei, Darussalam.

Methods: This was a cross-sectional descriptive and analytical study conducted at the maternal child health center in Brunei, Darussalam. The study group was comprised of 95 pregnant women attending the MCH clinic, Jubli Perak Sengkurong Health Centre, September 2010, using convenience sampling method. A self-administered questionnaire was used, after it was pre-tested and validated. Statistical analysis was done using SPSS version 16.

Results: Of the total study group, $97.9 \%$ responded to the questionnaire and participated in the study. All the women brushed at least twice daily. However, only 40.9\% flossed daily, 31.2\% brushed after meals and $26.9 \%$ had a dental check-up at least twice a year. The knowledge related to dental care was also poor among the pregnant women. Though the majority of them (96.8\%) agreed that women should have a dental check-up during pregnancy, only $55.9 \%$ actually practiced this. This raises serious concern since pregnant women may need extra oral and dental care due to susceptibility to gum diseases during pregnancy, which may contribute to low birth weight babies and premature births.

Conclusion: This study highlights important gaps in dental knowledge and practices related to oral and dental healthcare among pregnant women in Brunei, Darussalam. More intense dental health education, including oral health promotion in maternal child health centers can lead to improved oral and dental health, and ultimately pregnancy outcomes.

\section{Sunita Bamanikar}

Professor, Department of Pathology, Padmashree Dr.D.Y.Patil Medical College, Hospital and Research Center, Dr. D.Y. Patil Vidyapeeth, Pimpri, Pune 411018 Maharashtra, India. (Formerly Asso. Prof. Pathology, PAP Rashida Institute of Health Sciences, Universiti Brunei Darussalam).

E-mail: sunitarvind@hotmail.com

\section{Liew Kok Kee}

Medical Student, PAP Rashida Institute of Health Sciences, Universiti Brune Darussalam, Jalan Tungku link, Gadong BE 1410, Negara Brunei Darussalam.
Keywords: Attitude; Dental health; Knowledge; Practice; Pregnant women.

\section{Introduction}

\section{$\mathbf{P}$} regnant women are more susceptible to periodontal disease because of female reproductive hormonal influences. A few studies have demonstrated that periodontal disease may be associated with adverse pregnancy outcomes, such as premature birth and low birth weight. ${ }^{1-3}$ Prevention of oral and dental problems and their complications during pregnancy is possible through having pregnant women expressing appropriate knowledge, attitude and practice. This study provides a small insight into the country's current situation on oral and dental healthcare among pregnant women, and it will raise awareness on the importance of good oral and dental healthcare not only in pregnant women, but also in the general public.

The aim of the study was to assess women's knowledge and attitude of oral and dental healthcare during pregnancy and to examine their self-care practices in relation to their oral and dental health. In this way, deficiencies could be identified and recommendations could be formulated to improve dental education in antenatal care.

\section{Methods}

This is a cross-sectional, descriptive and analytical study. Ethical clearance was obtained from the institutional ethical committee and Medical and Health Research Ethics Committee at the Ministry of Health. The study was conducted over a one month period in September 2010 on all pregnant women attending the maternal child health clinic, Jubli Perak Sengkurong Health Centre; using convenience sampling method. A self-administered questionnaire was used, and it was pre-tested and validated prior to the commencement of the study. The questionnaire was broadly divided into four parts: (1) socio-demographic data consisting of age, ethnicity, education and job status; (2) knowledge; (3) attitude, and (4) practice of pregnant women on oral and dental health.

In this study, 95 patients were handed the questionnaire. Their ages ranged from $16-45$ years. The response rate was $97.9 \%$. The 
data were analyzed using the SPSS version 16. Descriptive and inferential statistics were used. Chi-square test was used to compare the difference in knowledge and practice related to oral and dental healthcare among the pregnant women by age group, educational level and job status. For all comparisons, statistical hypotheses were tested using the two-tailed tests; $p$-values $<0.050$ were considered statistically significant.

\section{Results}

Out of 95 samples, 93 participated in the study, which accounts for a response rate of $97.9 \%$. The variables of socio-demographic characters included age, ethnicity, education, and job status are illustrated in Table 1 . There was no significant association between all 6 practices with age, educational level or job status. All the women brushed at least twice daily. However, only 40.9\% flossed daily, 31.2\% brushed after meals (breakfast and dinner), and $26.9 \%$ had a dental checkup at least twice a year. Also the women express poor knowledge of dental care. (Fig. 1)

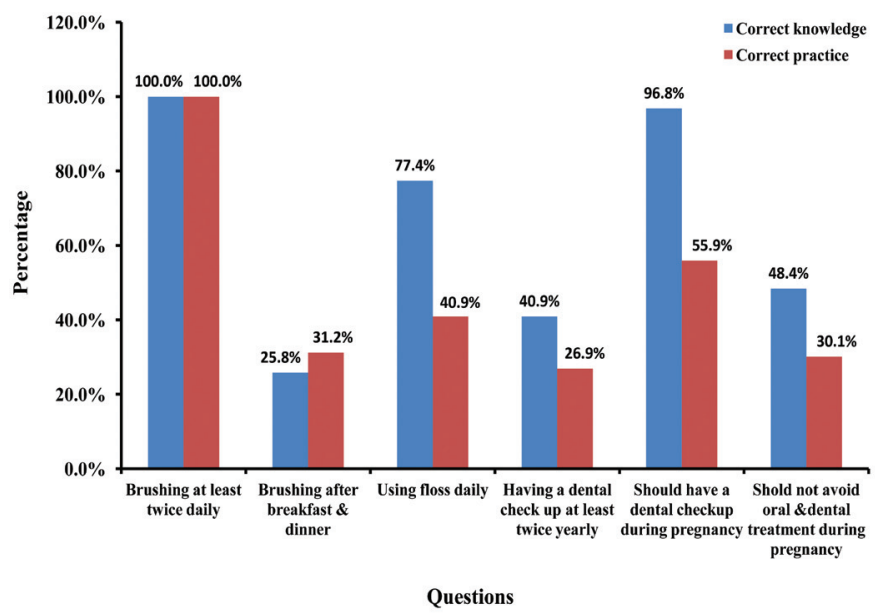

Figure 1: Knowledge and practice related to 6 oral and dental health cares of 93 respondents.

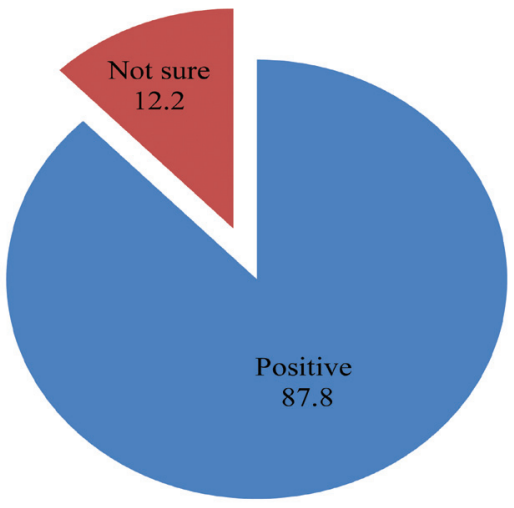

Figure 2: Attitude towards having a dental checkup in the future $(\mathrm{n}=41)$.

Table 1: Socio-demographic characteristics of 93 respondents.

\begin{tabular}{ll}
\hline Variable & $\mathbf{n}(\%)$ \\
\hline Age (year) & $04(04.3)$ \\
$16-20$ & $50(53.8)$ \\
$21-30$ & $37(39.8)$ \\
$31-40$ & $02(02.1)$ \\
$41-45$ & \\
Ethnicity & $89(95.7)$ \\
Malay & $04(04.3)$ \\
Filipino & \\
Education & $03(03.2)$ \\
Primary & $48(51.6)$ \\
Secondary & $16(17.2)$ \\
Pre Uni & $26(28.0)$ \\
Higher & \\
Job status & $60(64.5)$ \\
Yes & $33(35.5)$ \\
No &
\end{tabular}

Table 2. Comparison between having knowledge oral and dental treatment during pregnancy and age group, educational level and job status.

\begin{tabular}{|c|c|c|c|c|c|c|}
\hline \multirow{2}{*}{ Variable } & \multirow{2}{*}{$\mathbf{n}$} & Disagree & Agree & Not sure & \multirow{2}{*}{$\chi^{2}(d f)^{a}$} & \multirow{2}{*}{$p$-value } \\
\hline & & n (\%) & n (\%) & n (\%) & & \\
\hline Total & 93 & $13(14.0)$ & $45(48.4)$ & $35(37.6)$ & & \\
\hline \multicolumn{7}{|l|}{ Age (year) } \\
\hline $16-30$ & 54 & $7(13.0)$ & $26(48.1)$ & $21(38.9)$ & $0.15(2)$ & 0.928 \\
\hline $31-45$ & 39 & $6(15.4)$ & $19(48.7)$ & $14(35.9)$ & & \\
\hline \multicolumn{7}{|l|}{ Education } \\
\hline Primary and Sec & 51 & $8(15.7)$ & $16(31.4)$ & $27(52.9)$ & $14.02(2)$ & 0.001 \\
\hline Pre- $U$ and higher & 42 & $5(11.9)$ & $29(69.0)$ & $8(19.0)$ & & \\
\hline \multicolumn{7}{|l|}{ Job status } \\
\hline Yes & 60 & $8(13.3)$ & $35(58.3)$ & $17(28.3)$ & $7.39(2)$ & 0.025 \\
\hline No & 33 & $5(15.2)$ & $10(30.3)$ & $18(54.5)$ & & \\
\hline
\end{tabular}

Education=Educational level; Primary \& Sec=Primary \& secondary; Pre-U E bigher=Pre-university E higher education. 
The results from the responses to the 6 questions concerning knowledge and practice related to oral and dental healthcare indicate that the knowledge related to oral and dental treatment (e.g. filling, scaling, and extraction) during pregnancy was significantly associated with educational level and job status, as shown in Table 2. Alos, Fig. 2 shows the attitude of 41(44.1\%) pregnant women who have not had a dental check-up for the current pregnancy towards having a dental check-up in the future.

Table 3 shows the comparison between knowledge and practice of oral and dental healthcare among the pregnant women. Knowledge related to the frequency of brushing, flossing and brushing times was significantly associated with their practice (all $p$-values $<0.001)$. However, no significant association was found between the knowledge and practice of frequent dental checkup, having checkup during pregnancy, or avoiding oral and dental treatment during pregnancy.

Table 3: Comparison between knowledge and practice related to oral and dental healthcare.

\begin{tabular}{|c|c|c|c|c|}
\hline \multirow{2}{*}{$\begin{array}{l}\text { Knowledge } \\
\text { response }\end{array}$} & \multirow[t]{2}{*}{$\mathbf{n}$} & \multirow[t]{2}{*}{$\begin{array}{c}\mathbf{n}(\%) \\
\text { Practiced }\end{array}$} & \multirow{2}{*}{$\begin{array}{c}\begin{array}{c}\text { Not } \\
\text { Practiced }\end{array} \\
\mathbf{n}(\%) \\
\end{array}$} & \multirow{2}{*}{$\begin{array}{c}\chi^{2}(d f)^{a} \\
(p \text {-value })\end{array}$} \\
\hline & & & & \\
\hline \multicolumn{5}{|c|}{$\begin{array}{l}\text { Brushing at least } \\
\text { twice daily }\end{array}$} \\
\hline Total & 93 & $93(100)$ & - & - \\
\hline Correct & 93 & $93(100)$ & - & - \\
\hline Incorrect & - & - & - & - \\
\hline \multicolumn{5}{|c|}{$\begin{array}{l}\text { Brushing after } \\
\text { breakfast } \& \text { dinner }\end{array}$} \\
\hline Total & 93 & $29(31.2)$ & $64(68.8)$ & - \\
\hline Correct & 24 & $21(87.5)$ & $3(12.5)$ & $47.81(1)$ \\
\hline Incorrect & 69 & $8(11.6)$ & $61(88.4)$ & $(<0.001)$ \\
\hline \multicolumn{5}{|c|}{ Using floss daily } \\
\hline Total & 93 & $38(40.9)$ & $55(59.1)$ & - \\
\hline Correct & 72 & $37(51.4)$ & $35(48.6)$ & $14.63(1)$ \\
\hline Incorrect & 21 & $1(04.8)$ & $20(95.2)$ & $(<0.001)$ \\
\hline
\end{tabular}

${ }^{a}$ Chi-square test for independence

\section{Discussion}

The knowledge related to dental care such as brushing at least twice daily, use of floss daily, brushing after meals, and dental checkup at least twice a year was found to be poor among the pregnant women. Knowledge intervention in this area might be necessary. In comparison with a postnatal survey conducted in Australia, ${ }^{4}$ $26.4 \%$ of pregnant women did not receive dental care at least twice yearly. Majority of the pregnant women (96.8\%) agreed that women should have a dental checkup during pregnancy, but only $55.9 \%$ had done it for the current pregnancy. In the postnatal survey done in Australia, only $30 \%(n=116)$ of the women attended a dental clinic during pregnancy. This raises serious concerns as pregnant women may need extra oral and dental care due to susceptibility to gum disease during pregnancy. Studies have shown that gum disease may contribute towards the birth of low birth weight babies and premature births, ${ }^{5,6,7}$ The three most common perceived barriers against having a checkup as expressed by the $44.1 \%$ who have not had a check during the current pregnancy were; long waiting time at the government clinics $(53.7 \%)$, distantce from home to the clinics $(24.4 \%)$ and negative attitudes of medical workers (9.8\%). Other studies have reported the failure rate of attendance in dental clinics as $50 \%$, mainly due to work commitment. ${ }^{8}$ However, $87.8 \%$ of them had positive attitude towards having a checkup soon. This is in contrast to a similar study done in Iran, ${ }^{9}$ were $70 \%(n=224)$ of pregnant women had negative attitude of having a dental check-up in the future.

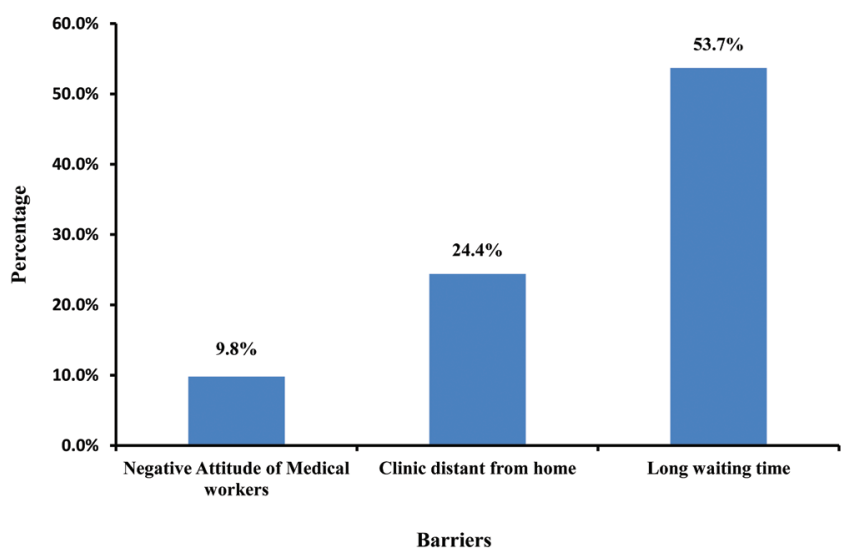

Figure 3: Perceived barriers to dental checkup $(\mathrm{n}=41)$.

Fig. 3 shows the perceived barriers against dental check-up by the 41 women who have not had a dental checkup for the current pregnancy.

Comparing the difference in knowledge of oral and dental treatment during pregnancy, those with higher education and employment expressed better knowledge. It is probable that social communication among them had influenced this increases in knowledge. Only $48.4 \%$ of pregnant women agreed that oral and dental treatment should not be avoided during pregnancy, while the rest either disagreed or were not sure. Women should not fear any dental intervention during pregnancy; indeed, specialists believe that common treatment during pregnancy is not harmful for pregnant women or the unborn baby. ${ }^{10}$

In comparison between knowledge and practice of oral and dental healthcare, knowledge about frequency of brushing, flossing and brushing after meals was significantly associated with practice (all $p<0.001$ ). This shows that proper education on oral and dental healthcare among the pregnant women may lead to correct practice of oral and dental health. Pregnant women are more susceptible to periodontal disease like gingivitis because of female reproductive hormonal influences. ${ }^{11}$ Pregnancy is a time when women may be more motivated to make health changes. Therefore, maintaining good oral health during pregnancy is important, apart from reducing the risk of adverse pregnancy outcomes, but it also improves general health of both the mother and her infants. ${ }^{12}$ 
This study has the limitation of relying on self-reported data and therefore is subject to bias. Furthermore, the study was carried out in one clinic only, therefore the results may not be sufficient to conclude for the whole pregnant population of Brunei.

\section{Conclusion}

This study observed key gaps in knowledge and practice of oral and dental healthcare among the pregnant women. Long waiting time in the government clinic ranked the first perceived barrier against having a dental checkup during pregnancy. Whether more intensive oral and dental health education in pregnancy can lead to improved oral and dental health, and ultimately better pregnancy outcomes, would require further study.

\section{Acknowledgements}

We would like to express our gratitude to Dr. Shamsulniza bin Shamsuddin for her guidance at the dental clinic, Dr. Lin Naing Mohd Ayub Sadiq and Dr. Mohd Moshaddeque Hossain for their help with biostatistics. No financial grant was obtained for this study.

\section{References}

1. Offenbacher S, Katz V, Fertik G, Collins J, Boyd D, Maynor G, et al. Periodontal infection as a possible risk factor for preterm low birth weight. J Periodontol 1996 Oct;67(10)(Suppl):1103-1113.
2. Jeffcoat MK, Geurs NC, Reddy MS, Cliver SP, Goldenberg RL, Hauth JC. Periodontal infection and preterm birth: results of a prospective study. J Am Dent Assoc 2001 Jul;132(7):875-880.

3. López NJ, Da Silva I, Ipinza J, Gutiérrez J. Periodontal therapy reduces the rate of preterm low birth weight in women with pregnancy-associated gingivitis. J Periodontol 2005 Nov;76(11)(Suppl):2144-2153.

4. Thomas NJ, Middleton PF, Crowther CA. Oral and dental health care practices in pregnant women in Australia: a postnatal survey. BMC Pregnancy Childbirth 2008;8:13.

5. Khader YS, Táani Q. Periodontal diseases and the risk of preterm birth and low birth weight: a meta-analysis. J Periodontol 2005 Feb;76(2):161-165.

6. Mokeem SA, Molla GN, Al-Jewair TS. The prevalence and relationship between periodontal disease and pre-term low birth weight infants at King Khalid University Hospital in Riyadh, Saudi Arabia. J Contemp Dent Pract 2004 May;5(2):40-56.

7. Sánchez AR, Kupp LI, Sheridan PJ, Sánchez DR. Maternal chronic infection as a risk factor in preterm low birth weight infants: the link with periodontal infection. J Int Acad Periodontol 2004 Jul;6(3):89-94.

8. Al Mullahi A, Mendoza LF, Al Wahaibi MC. Audit on Patient's Attendance Pattern, Reasons for Failed Appointments and Waiting Time at Oral Health Department. Oman Med J 2012; Jan 27(1) (Suppl):75-100.

9. Hajikazemi E, et al. The relationship between Knowledge, Attitude and Practice of Pregnant Women about Oral and Dental Care. European Journal of Scientific Research 2008;24(4):556-562.

10. American Academy of Periodontology 2010; Baby steps to a healthy pregnancy and on time delivery. [Online] Available from: http://www.perio.org/consumer/ pregnancy.htm\#4 [Accessed 2 August 2010]

11. Deasy MJ, Vogel RI. Female sex hormonal factors in periodontal disease. Ann Dent 1976;35(3):42-46.

12. Silk H, Douglass AB, Douglass JM, Silk L. Oral health during pregnancy. Am Fam Physician 2008 Apr;77(8):1139-1144. 